\title{
PROPOSED DATABASE SYSTEM MODEL TO SUPPORT HEALTHY AGING
}

\author{
Sérgio de Vasconcelos Filho and Cristine Martins Gomes de Gusmão \\ Department of Biomedical Engineering, Federal University of Pernambuco \\ Recife, Brazil
}

\begin{abstract}
It is agreed that the elderly population has increased considerably in Brazil and worldwide. Research has shown that the adoption of electronic patient records has doubled. Thus, a complex issue is perceived: the aging of the population through the increase of life expectancy and, as a consequence, the progressively exorbitant generation of medical data from society as a whole. This problem is reinforced by one of Agenda 2030's sustainable development goals, which discusses health and well-being. The proposal of the model will be based on the patients' medical information through the public health service, and will serve both to make inferences of the population, in general, as well as more individualized deductions. The proposed model is also expected to support demographic research, epidemic control, endemic diseases and others, through statistical analysis of its data. The application of the methodology with the previously described materials developed in the UML class diagram. The range of possibilities of the proposed system is notorious, since it is possible to increase the quantity and quality of the information retained by it, so that it can infer new data sets for the improvement and maintenance of the well-being of both the individual and the population as a whole.
\end{abstract}

\section{KEYWORDS}

Blockchain, Unified Modeling Language, Sustainable Development Goals

\section{INTRODUCTION}

It is agreed that the elderly population has increased considerably in Brazil and worldwide. This is supported by projections that by 2030 the elderly Brazilian population will be the sixth largest in the world (IBGE, 2018) and that by 2050 the number of people over 60 could reach two billion (UNITED NATIONS, 2004). Concomitantly with this population growth, there is an unprecedented increase in data production, including health. In fact, the use of electronic patient records has generated massive data sets. Research from the American Hospital Association showed that adoption of these registrations doubled from 2009 to 2011, in part as a result of funding provided by the Health Information Technology Act for Economic and Clinical Health 2009 (Charles et al, 2012). Most of them now contain quantitative, qualitative, and transactional data, illuminating the source of this explosion of new data.

Thus, a complex issue is perceived: the aging of the population through the increase of life expectancy and, as a consequence, the progressively exorbitant generation of medical data from society as a whole. This problem is reinforced by one of Agenda 2030's sustainable development goals, specifically Goal 3, by aiming to "Ensure a healthy life and promote well-being for all at all ages" (UNITED NATIONS, 2015). Thus, the need for increasingly complex, robust and comprehensive healthcare systems is explicit. Otherwise, it will be difficult to treat disease surveillance and control globally.

\section{GOALS}

The proposal of the model will be based on the patients' medical information through the public health service, and will serve both to make inferences of the population, in general, as well as more individualized deductions. The proposed model is also expected to support demographic research, epidemic control, 
endemic diseases and others, through statistical analysis of its data. The purpose of the model is to support Healthy Aging policies and contribute to achieving the goals of the Sustainable Development Goals (SDGs) in order to improve the quality of life of the population as a whole.

\section{THEORETICAL FOUNDATION}

Blockchain is a distributed registration technology aimed at decentralization as a security measure, originally developed for Bitcoin cryptocurrency (Satoshi, 2008). The principle of its operation can be explained using Bitcoin transaction principles through digital wallet concepts. If a Bitcoin transaction, for example, is made from wallet $\mathrm{A}$ to wallet $\mathrm{B}$, this information will be shared simultaneously with all other wallets in the Blockchain network. Information from a transaction is combined into a block of data, marked with a timestamp and added as a new block to the existing Blockchain network. At the same time, this transaction is verified and confirmed by all portfolios involved (Schneie, 2004).

UML is a set of rules, diagrams and structures that assist in the analysis and development of the software design project (Simões et al., 2010). We will focus here on the class diagram, one of the existing diagrams within the UML, which is a representation of the structure and relationships of the object model classes. In addition, the classes have diverse interactions with each other, some of which are represented in Figure 1.

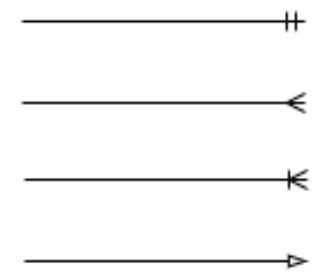

Figure 1. Types of arrows used in this research

The first arrow, located at the upper end of Figure 1, is used in cases where only one object of the class to which the arrow is attached is used. The second explicit arrow is then used when more than one object of the linked class is requested. Analogously is the explanation of the following arrow, differing only in the fact that it necessarily requires the use of another object of the connected class. There is also the arrow for subclass representation, the last one represented in the figure.

To continue the work of the Millennium Development Goals, the Sustainable Development Goals (SDGs) were implemented in 2015. In all, there are 17 goals that cover the old MDG goals and also include more complex and interlinked issues such as: global warming; peace and justice; industry, innovation and energy, among others (UNITED NATIONS, 2015). In this sense, the SDG Goal 3 deals specifically with health and well-being. In line with the proposals, there are also secondary goals, such as Objective 3.8 and 3.d, which both address achieving universal health coverage and strengthening the capacity of all countries to warn of health risks, respectively (UNITED NATIONS, 2018).

\section{MATERIALS AND METHODS}

Initially, studies of falls in the elderly population (Filho, S. and Gusmão, C, 2018) (Filho, S. and Gusmão, C, 2019) reported inferences about the relationship of risk factors associated with falls with deaths caused by falls based on information available in the DATASUS database. The brainstorm method was used among the authors for the initial survey of the functional and non-functional requirements for the initial draft of the model. That done, the construction of the UML diagram followed. We sought to take DATASUS as a starting point, seeking, however, innovation in the themes of data capture, processing and display. 
The information initially studied allowed the development of important and necessary characteristics for the proposed database modeling. Once in possession of them, the SDG studies corroborate the need for a vision of improving the quality of life in the systems proposed to the population. Therefore, the list of entities and attributes considered essential was established in order to support the discussion and elaboration of the UML class model.

\section{RESULTS AND DISCUSSION}

The application of the methodology with the described materials resulted in the class diagram shown in Figure 2. Thus, it is argued that public key cryptography, together with blockchain technology, permeates the entire system model. The model has five application areas: individual, local, family, patient and professional. In order to ensure data anonymity but still make correlations, it is used in the model to iterate public key cryptography, which is represented by the " $p$ " interface between the model variable names.

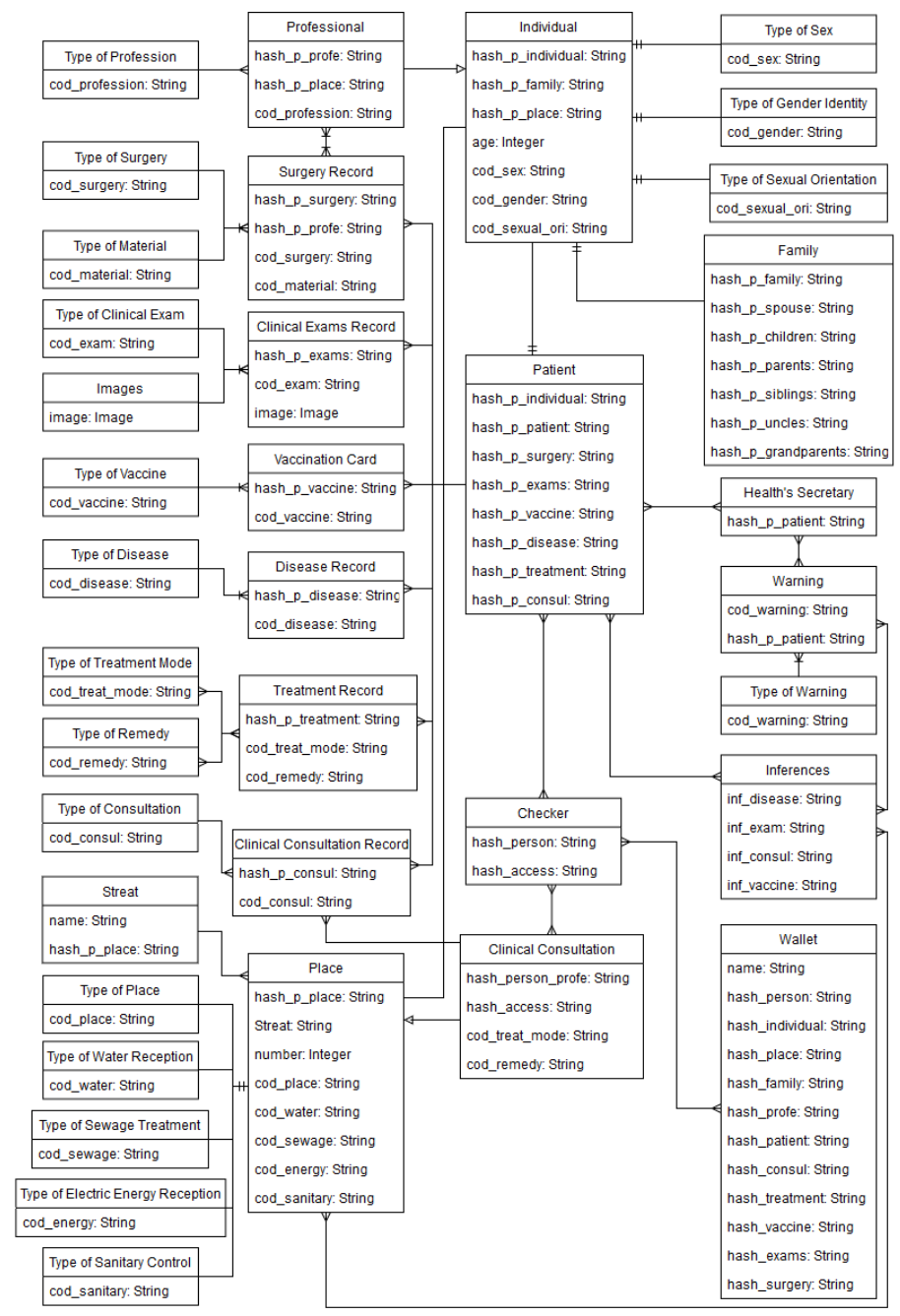

Figure 2. Class diagram

Beginning with the analysis by the "individual" class, it is clear that she has information about age, gender, gender identity and sexual orientation. The decision to insert this information into the system model follows the line of reasoning for making inferences from this data and the foundation of research in the area with them. In addition, there is the subclass "professional", which stores the information of the professional life of the individual. 
The analysis is similar for the "family" class, where it records the key of family and close relatives. A strong argument for the relevance of these types of data is the field of genetics, in the sense that there is a possibility of tracking genetic diseases in the family or even larger groups. The "places" category stores local information such as water reception, sewage treatment, electricity and sanitary control reception, and the street itself, being able to give access to keys from other locations. The "patient" class also records and stores the individual's entire health history, such as surgeries performed, drug prescriptions and others. In order for the individual to give other institutions access to their information, they carry the access codes in QRcode format on a piece of paper or in card format.

\section{CONCLUSION}

The range of possibilities of the proposed system is notorious, since it is possible to increase the quantity and quality of the information retained by it, so that it can infer new data sets for the improvement and maintenance of the welfare of both the individual and the population. as a whole. It is also noted that the model is able to help meet the SDG objectives 3.8 and 3.d, considering its early warning capability, through inferences, and the reduction and management of health risks, being permeated throughout proposed system.

\section{ACKNOWLEDGEMENT}

The project team thanks the SABER Educational and Social Technologies group of the Federal University of Pernambuco (UFPE) for the infrastructure available to carry out the activities necessary for the correct conduct of the studies.

\section{REFERENCES}

IBGE. 2018. Projeção da População 2018: número de habitantes do país deve parar de crescer em 2047. [online] Agência Notícias IBGE. Available at: https://agenciadenoticias.ibge.gov.br/agencia-sala-de-imprensa/2013-agenciade-noticias/releases/21837-projecao-da-populacao-2018-numero-de-habitantes-do-pais-deve-parar-de-crescer-em2047 [Accessed 12 Sep. 2019].

Charles, D. et al. 2012. Electronic Health Record Systems and Intent to Attest to Meaningful Use Among Non-federal Acute Care Hospitals in the United States: 2008-2011. [online] Office of the National Coordinator for Health Information Technology. Available at: http://www.healthit.gov/media/pdf/ONC_Data_Brief_AHA_2011.pdf [Accessed 10 Oct. 2019].

DEVMEDIA. 2010. Introdução a UML. [online]. Available at: https://www.devmedia.com.br/introducao-a-uml/6928 [accessed 28 Aug. 2019].

Filho, S. and Gusmão, C. 2018. Analysis of falls in the population of the state of Pernambuco. R-BITS, vol. 8, 1st ed., pp. 28-39, 2018.

Filho, S. and Gusmão, C. 2019. Relation between deaths due to fall in the elderly population and associated risk factors. 14th Iberian Conference on Information Systems and Technologies (CISTI), Coimbra, Portugal, 2019, pp. 1-6.

Satoshi, N. 2008. Bitcoin: A Peer-to-Peer Electronic Cash System. [online]. Available at: https://bitcoin.org/bitcoin.pdf [Accessed 3 Sep. 2019].

Schneie, B. 2004. Cryptanalysis of MD5 and SHA: Time for a New Standard. [online] Computerworld. Available at: https://www.computerworld.com/article/2566208/opinion--cryptanalysis-of-md5-and-sha--time-for-a-newstandard.html [Accessed 14 Aug. 2019].

UNITED NATIONS (1). 2015. Transforming our world: the 2030 Agenda for Sustainable Development. [online] Sustainable Goals Development Knowledge Plataform. Available at: https://sustainabledevelopment.un.org/post2015/transformingourworld [Accessed 17 Sep. 2019].

UNITED NATIONS. 2004. World Population Prospects: The 2004 Revision. Uni. Nat. Pub. New York.

UNITED NATIONS. 2018. Sustainable Development Goal 3. [online] Sustainable Goals Development Knowledge Plataform. Available at: https://sustainabledevelopment.un.org/sdg3 [Accessed 7 Aug. 2019].

WORLD HEALTH ORGANIZATION. 2002. Active ageing: a policy framework. [Online]. Available at: https://www.who.int/ageing/publications/active_ageing/en/ [Accessed 20 Sep. 2019]. 